\title{
La agenda de género en Arabia Saudí e Irán: factores para una socialización internacional Carlos Ortega Sánchez*
}

\section{RESUMEN}

En el presente artículo se proceden a analizar los factores explicativos de la incorporación de las cuestiones de género en las agendas políticas de Arabia Saudí e Irán desde una perspectiva doméstica e internacional. Para la comprensión de la adquisición de estas políticas atenderemos tanto a la internacionalización de la agenda de género como a las luchas de los movimientos sociales en ambos estados, lo cual ha presentado dos modelos: el saudí, basado en la apropiación del discurso de las activistas y en su silenciamiento; y el iraní, mucho más modesto a escala doméstica e internacional pero directamente relacionado con las demandas de dichos movimientos sociales a partir de una integración de los mismos en las dinámicas de poder.

Para ello, en primer lugar, se estudiarán las trayectorias de las políticas de género de ambos estados; en segundo lugar, se procederá al estudio de la rivalidad regional de ambos estados bajo la construcción de identidades polarizadas; $y$, finalmente, se analizará la incorporación de políticas de género como modelo de legitimación del liderazgo regional.

\section{Palabras clave}

Agenda de género;Arabia Saudí; Irán; rivalidad regional;Visión2030

\section{*Carlos}

ORTEGA

SÁNCHEZ,

Doctorando en

Ciencias Sociales

y Relaciones

Internacionales en

la Universidad de

Estambul. Correo

electrónico:

cortegasan93@

gmail.com

Recibido:

31/03/2019

Aceptado:

02/09/2019

\section{Titue}

The gender agenda in Saudi Arabia and Iran: factors for an international socialization

\begin{abstract}
The present article seeks to analyse the explanatory factors of gender mainstreaming within the political agendas of Saudi Arabia and Iran from both a local and an international perspective. To understand the acquisition of these policies, this investigation focuses on the internationalization of the gender agenda and on the demands of the social movements in both states. On this basis, two different models have emerged: the Saudi model which is based on the appropriation of the activists' discourse and its silencing; and the Iranian model which is more modest at local and international scale, but it is directly related to the demands of the social struggles by means of an operational integration with each one of them in the power dynamics.
\end{abstract}

To do so, in the first place, it will be explored the trajectories of the gender policies of these Member States; secondly, this will be followed by the study of the regional rivalry between the two states under the construction of polarized identities; and, finally, it will be analysed the incorporation of gender policies as a legitimation model of regional leadership.

\section{KEYWORDS}

Gender agenda; Saudi Arabia; Iran; regional rivalry;Vision2030.

DOI:

http://doi.org// 0.15366/relacionesinternacionales2019.42.007

Formato de citación recomendado:

ORTEGA SÁNCHEZ, Carlos. “La agenda de género en Arabia Saudí e Irán: factores para una socialización internacional”, en Relaciones Internacionales, $n^{\circ}$ 42, 2019, pp. I 19-140. 


\section{I}

\section{ntroducción}

Desde el nombramiento de Muhammad Bin Salman como heredero al trono de Arabia Saudí en junio de 2017 , se ha producido un giro notable en la política saudí tanto a nivel regional como internacional y doméstico, siendo el pilar fundamental de este giro la rivalidad con Irán. Si bien la rivalidad entre ambos estados ha estado vigente desde la revolución iraní de 1979, en la última década la tensión ha escalado. A nivel regional, Arabia Saudí ha adoptado una política de injerencia -en la guerra de Yemen, en el bloqueo de Qatar o en las elecciones de Líbanomientras que, a nivel internacional, ha llevado a cabo una fuerte actividad diplomática cuyo objetivo es difundir su plan de reforma económica Vision2030 mientras promueve el aislamiento del país vecino, el cual ha tenido desde el nacimiento de la República Islámica una activa política regional de injerencia y exportación de la revolución.

MBS ha procedido a implantar una serie de reformas polémicas cuyo objetivo principal es defender ante la comunidad internacional sus intenciones de disminuir la gran brecha de género que ha existido históricamente en Arabia Saudí. Para ello, el príncipe ha procedido a permitir a las mujeres saudíes conducir al mismo tiempo que a denunciar a Irán ante la comunidad internacional, legitimando así su política regional. En el presente escrito analizaremos la incorporación de políticas de género en las agendas de ambos países a través de un estudio de su trayectoria política, de su identidad y de las demandas de los movimientos sociales feministas, todo ello condicionado por una creciente rivalidad regional.

La internacionalización de la agenda de género ha tenido como consecuencia la adopción de ésta por parte de Arabia Saudí e Irán. Analizar la trayectoria de incorporación de políticas de género por parte de ambos estados es de elevada relevancia para comprender la relación de los movimientos feministas locales y nacionales y de sus demandas con las medidas de los estados. Al mismo tiempo, analizar las reformas arroja luz a la hora de comprender los intereses a nivel regional e internacional en el contexto de una escalada de la hostilidad.

Preguntándonos, "¿cuáles son los factores explicativos de la incorporación de cuestiones de género a la política internacional de Arabia Saudí e Irán?" procederemos a desarrollar el presente estudio situándolo en el marco teórico de la teoría de las Relaciones Internacionales, especialmente desde los conceptos del "ciclo de la norma" y de "socialización internacional" desarrollados por Kathryn Sikkink y Martha Finnemore, los cuales se aplican a la situación actual de Arabia Saudí e Irán en materia del presente artículo. A partir de ello, procederemos a analizar la trayectoria de la incorporación de las cuestiones de género en la política internacional tanto saudí como iraní a través del estudio de sus múltiples factores estableciendo la rivalidad entre ambos como factor determinante en el desarrollo de nuevas políticas de género por parte de ambos estados.

El presente artículo tiene tres puntos a tratar: las políticas de género en Arabia Saudí en relación con los movimientos feministas internos y la agenda de género internacional, la trayectoria de las políticas de género iraníes en relación con los movimientos feministas internos y la agenda de género internacional y, la rivalidad entre ambos estados como un factor determinante en el desarrollo de dichas políticas. 
El análisis de la trayectoria reformista en materia de género de los dos estados, con especial atención a las últimas dos décadas y, más concretamente a las reformas posteriores a $201 \mathrm{l}$ y a la llegada de Muhammad bin Salman al poder en Arabia Saudí, tiene como objetivo el contraste con el papel de los movimientos feministas de cada estado como emprendedores normativos, tratando un tema de absoluta vigencia con desde una perspectiva de género.

\section{I.Trayectorias políticas en las agendas de género de Irán y AS}

\section{I.I.El modelo iraní}

\section{a) Género y reforma en Irán}

La tradición iraní en cuanto a políticas de género tiene un largo recorrido. Si bien en el presente escrito dicha trayectoria no puede tratarse con detalle, es necesario especificar que dicho recorrido se ha saldado con una amplia presencia de las mujeres en la vida pública. Desde comienzos del siglo $\mathrm{XX}$ e incluso desde la construcción del estado moderno, las mujeres iraníes han participado de forma muy activa en la política a partir de diversas estrategias. Según Labani Motlagh, las políticas de ambos shahs estuvieron orientadas en torno a tres puntos que fundamentaron una "revolución desde arriba"|: promoción e integración de las mujeres iraníes en la vida pública, prohibición del velo y glorificación de la maternidad. El carácter autoritario de ambos gobiernos y la experiencia reformista del breve gobierno de Mossadegh marcó la constante presencia en la vida pública de las mujeres iraníes, la cual ha continuado hasta la actualidad².

La República Islámica de Irán, a pesar de constituirse como un estado profundamente patriarcal, ha conseguido tender un puente entre el poder y la modernidad que el Shah no logró, creando un discurso sobre la modernidad polivalente bajo los ideales de la revolución constante. En ésta, las mujeres tienen un papel activo protagonista reforzando las relaciones de poder, pero de la misma manera generando resistencia. Dichas relaciones de poder se caracterizan por un carácter censurador - vigilar y castigar- y por la existencia de un contrapoder, en este caso feminista, que ha generado una serie de identidades y subjetividades que transgreden los espacios reservados por el patriarcado para participar de forma activa en la política, la sociedad y la economía ${ }^{3}$.

\section{b) Política de género en la era Rouhani}

Hassan Rouhani abrió tanto una etapa de modernización y de socialización internacional como clausuró una etapa previa en la que los derechos de las mujeres fueron en retroceso bajo el gobierno de Mahmoud Ahmadineyad. La "Campaña del Millón de Firmas”, destinada a luchar contra las leyes discriminatorias iraníes, se saldó con una dura represión del gobierno, si bien ha tenido reconocimiento internacional y ha sido base para el desarrollo de nuevas estrategias de

\footnotetext{
Con término "revolución desde arriba" nos referimos a una serie de reformas políticas y sociales impuestas por una élite. La llamada Revolución Blanca iraní, que contextualiza las medidas de género llevadas a cabo por el Shah Reza Pahlavi en el contexto de un sistema autoritario, es uno de los principales ejemplos de "revolución desde arriba".

2 FARZAMNIA, Nadereh, Irán: De la Revolución Islámica a la Revolución Nuclear, Síntesis, Madrid, 2009, pp. I29, I9I, 228. LABANI MOTLAGH, Sepideh, Los movimientos de mujeres feministas en Irán: un análisis desde la perspectiva de la teoría feminista, Universidad Autónoma de Madrid, Madrid, 20I5, pp. 298-23I, 338, 34I. NAYEREH, Tohidi, “Women's rights and feminist movements in Iran” en International Journal of Human Rights, 2016: http://sur.conectas.org/en/womens-rights-feminist-movements-iran/ [Consultado el 26 de agosto de 20 I8].

3 McCALL, Corey, COLLEGE, Elmira, “Ambivalent Modernities: Foucault's Iranian Writings Reconsidered”, en Foucault Studies, I5, 20I3, p. 30. SKORNICKI, Arnault, La Gran Sed de Estado: Michel Foucault y las Ciencias Sociales, Dado, Madrid, 20I7, p. 7I.
} 
acción ${ }^{4}$.

La llegada de MBS al poder en Arabia Saudí parece haber condicionado de forma notable las políticas de género de Hassan Rouhani. Según una serie de artículos publicados en el periódico estadounidense The New York Times, todos ellos a favor del heredero al trono saudí y de sus reformas, Irán ha tratado de competir con Arabia Saudí en una "carrera" por ver quién da más derechos a las mujeres, carrera que ya ha perdido ${ }^{5}$. La administración de Rouhani, en un momento crítico como el actual debido al rechazo del gobierno estadounidense del JCPOA, a la reimposición de duras sanciones y al alineamiento de las políticas de Donald Trump y MBS en la región, parece haber reaccionado a esta competitividad en la incorporación del género a su agenda mediante dos medidas: permitir a las mujeres acceder a campos de fútbol ${ }^{6}$ y permitir a las levantadoras de peso participar en competiciones internacionales ${ }^{7}$.

Si la primera medida ha sido recibida dentro del panorama internacional, como se ve en ambos artículos de TNYT, como respuestas a las medidas de MBS, la segunda ha sido vista como

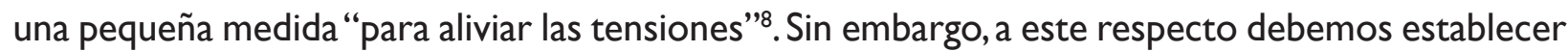
una diferencia muy relevante: el debate sobre la participación de las iraníes en el deporte se remonta a los inicios de la década de 1980. Personalidades como Faezeh Hachemi, vicepresidenta del Consejo Nacional Olímpico y presidenta de Solidaridad entre las Mujeres Deportistas de los Países Musulmanes, han abogado por el derecho a practicar las mismas actividades que los hombres incluso en el contexto de la segregación de género. A pesar de las reticencias de los sucesivos gobiernos islámicos, las mujeres iraníes, desde el activismo a múltiples niveles - tanto en las calles como en lo académico, en redes sociales o mediante la conquista de espacios o medios de comunicación - han creado una resistencia al poder ${ }^{9}$. Por ello, a la hora de considerar la incorporación de esta política de género por parte de gobierno iraní, no debemos verlo tanto como un cambio de paradigma hacia el reformismo por la presión internacional sino como un florecimiento de un debate nacional de gran riqueza que se ha perpetuado y crecido en las últimas cuatro décadas.

\section{c) El emprendimiento normativo en Irán ${ }^{10}$}

A pesar de construir el gobierno islámico una identidad de género que utiliza a las mujeres como símbolo, $y$, al igual que ha ocurrido en los últimos años en Arabia Saudí, las mujeres acaban

4 LABANI MOTLAGH, Sepideh, Los movimientos de mujeres...,op.cit., pp. 366-393.

5 HAKAKIAN, Roya, “The Iran-Saudi Arabia Rivalry Has a Silver Lining”, en NY Times, 27 de diciembre de 20I7: https://www.nytimes. com/2017/I2/27/opinion/iran-saudi-rivalry-women.html [Consultado el 10 de junio de 20I8] BARNARD, Anne, ERDBRINK, Thomas, "Iran and Saudis' Latest Power Struggle: Expanding Rights forWomen”, en NYTimes, 29 de diciembre de 20I 7: https://www.nytimes.com/20I 7/I2/29/ world/middleeast/iran-saudi-women.html [Consultado el 10 de junio de 2018]

6 HOMEWOOD, Brian, “Iran's Rouhani pledges women to get access to stadiums: FIFA chief”, en Reuters,2 de marzo de 20I8: https://www. reuters.com/article/us-soccer-fifa-iran/irans-rouhani-pledges-women-to-get-access-to-stadiums-fifa-chief-idUSKCNIGEIE] [Consultado el 10 de junio de 2018]

7 DW ENGLISH, “Iranian women look to conquer world of weightlifting”, 24 de abril de 2018 https://www.youtube.com/watch?v=IOb_QKSm2rk/ https://www.dw.com/es/actualidad/s-30684 [Consultado el I5 de julio de 20I8]

8 BARNARD,Anne, ERDBRINK, Thomas, “Iran and Saudis' Latest Power Struggle...”, op.cit.

9 MERINERO MARÍN, María José, Resistencia Creadora en Irán, Biblioteca Nueva; Universidad de Extremadura, Madrid, 2007, pp. I89-I90.

10 Con "emprendimiento normativo" nos referimos al término de Kathryn Sikkink y Martha Finnemore que se refiere a la consciencia de la necesidad de transformar algo que se considera como "inapropiado" en "apropiado" a partir de una modificación del consenso intersubjetivo dominante. Para ello los "emprendedores normativos", a partir de los movimientos sociales, construyen el marco cognitivo sobre el que cambiar la concepción de lo que es percibido como "bueno". Para esta transformación pueden servirse de actuaciones consideradas "inapropiadas" para replantear la diferencia entre "lo apropiado" y "lo inapropiado". FINNEMORE, Martha, SIKKINK, Kathryn, "International Norm Dynamics and Political Change”, en International Organization at Fifty: Exploration and Contestation in the Study of World Politics, I998, PP. 896-901. 
por constituir "una identidad como sujeto autónomo a través de un análisis crítico y de una reinterpretación de la historia, de las tradiciones culturales y de sus fundamentos ideológicos y religiosos para encontrar la autenticidad del mensaje islámico"।!.

Históricamente, las iraníes, que se convirtieron durante la revolución y sus años posteriores en protagonistas, combaten hoy contra la segregación de género. De esta manera, en los últimos años, el feminismo se ha constituido como una fuerza de desarrollo que ha incluido a las islamistas en las demandas, uniéndose las feministas laicas ${ }^{12}$ con las islámicas con el objetivo de acabar con el modelo jerárquico patriarcal consolidado bajo la interpretación religiosa que ha legitimado la autoridad de los hombres sobre las mujeres. El surgimiento del postislamismo, movimiento basado en la negación del Velayat-e Faqih, que impone la jurisprudencia del clero chií como custodia de la ciudadanía iraní, ha abierto nuevas formas de lucha conjunta ${ }^{13}$.

El crecimiento de los movimientos feministas se ha visto acompañado de una diversidad de estrategias favorecidas por los amplios campos de acción abiertos a partir de su participación en el sistema jurídico, en su participación política o en la actividad social. La gran presencia de mujeres en el ámbito académico, que supera el $60 \%$ de la población universitaria, ha favorecido el establecimiento y desarrollo de debates muy nutridos en tres campos principales: la demanda por el cumplimiento de la igualdad de género presente en la Constitución iraní, la aplicación de la ijtihad a las nuevas realidades sociales —es decir, la aplicación de la diversidad interpretativa del Corán a nuevos debates - y la denuncia de las incoherencias en las valoraciones jurídicas de las mujeres dependiendo del ámbito ${ }^{14}$. Marineh Ghorji, nombrada por el Ayatollah Jomeini para la redacción de la Constitución entre otros, ha abogado desde sus inicios por la rebelión feminista en todos los ámbitos y sobre la necesidad de interpretar el Corán desde esta perspectiva. Como puede verse, las mujeres iraníes, además de en la resistencia, han formado parte activa de los gobiernos revolucionarios desde el principio, eludiendo el carácter paternalista del estado.

Sin duda una de las principales estrategias de ocupación del espacio público patriarcal por parte de las mujeres es a partir de la prensa, en la que, a través de revistas como Farzaneh (Mujer Virtuosa), Yens-e dovom (El segundo sexo), Zanan (Las mujeres) o Payam-e zan (El mensaje de la mujer), la cual desdeña el feminismo occidental, han basado sus demandas en la igualdad desde lo científico, lo político y lo cultural ${ }^{1516}$.

La incorporación del género en la agenda política de Irán en la última década ha sido impulsada por la rivalidad con Arabia Saudí, siendo éste un factor determinante. Sin embargo, la política de género en Irán responde a una dinámica completamente distinta, basada en una

\footnotetext{
I LABANI MOTLAGH, Sepideh, Los movimientos de mujeres..., op.cit., p. 325.

12 A pesar de que en muchos campos la acción es conjunta, además del feminismo islamista libertario nos encontramos con el feminismo no islamista cuya mayor representante es Shirin Ebadi, jurista y profesora de la Universidad de Teherán, la cual lucha contra las incoherencias del estatuto jurídico de las mujeres iraníes y contra el régimen patriarcal.Además, la autora ha dedicado su carrera a la defensa de los derechos humanos. BBC NEWS, «Profile: Shirin Ebadi», 27 de noviembre de 2009: http://news.bbc.co.uk/2/hi/middle_east/3।81992.stm [Consultado el 0 I de septiembre de 2018]

13 MERINERO MARTÍN, María José, Irán: hacia un desorden prometedor, Los Libros de la Catarata, Madrid, 200 I, pp. I 96 - I97.

14 MERINERO MARÍN, María José, Resistencia Creadora en Irán..., op.cit., Pp. I7I-I 72.

15 Ibídem, p. 191.

16 LABANI MOTLAGH, Sepideh, Los movimientos de mujeres..., op.cit., p. 356.
} 
percepción de las relaciones de poder que Foucault integró en sus teorías de biopolítica, en la que la resistencia al poder se hace mediante la creación, la transformación de la situación y la participación activa en los procesos políticos. Todo parte de la base de que la sociedad iraní es una sociedad civil que en las últimas décadas se ha fortalecido y modernizado de forma ajena al régimen, en una creciente tendencia a la conquista del espacio público y político a través del rechazo del monopolio de poder del Velayat-e Faquih y del sistema patriarcal que lo legitima. También es necesario reconocer que, en palabras de María Jesús Merinero ${ }^{17}$, "existe espacio en la República Islámica, para el desacuerdo y la heterogeneidad de perspectivas”. La extensión de una diversidad de perspectivas críticas ha consolidado un fuerte contrapoder caracterizado por una estrategia de resistencia civil feminista que implica el reconocimiento de sus demandas en la agenda política nacional mediante el ijtihad feminista, la prensa y el activismo; e internacional mediante campañas nacionales de repercusión internacional, como la Campaña del Millón de Firmas.

\section{I.2. El modelo saudí}

\section{a) Género y reforma en Arabia Saudí en las últimas décadas}

La trayectoria de las políticas de género en Arabia Saudí desde su unificación en 1932 ha estado históricamente marcada por un gobierno blindado ante cualquier tipo de reforma. Desde el reinado del rey Faisal, entre 1964 y 1975, hubo un gran impulso reformador rápidamente frenado con su asesinato y que tuvo como consecuencia un estancamiento y retroceso de las políticas sociales ${ }^{18}$. Durante la década de 1990, la presencia de clérigos islamistas en las instituciones se saldó con el aumento de las leyes de segregación de género, defendida tanto desde la interpretación wahabí de los textos del islam como desde la tradición saudí'

Con el inicio del siglo XXI, la monarquía saudí ha venido asentándose en su identidad cultural que intercala religión con tradición y con neoconservadurismo social. Sin embargo, su progresiva inclusión en la sociedad internacional y su creciente papel como aliado territorial estadounidense han hecho de su rol en lo internacional más activo, implicándose en la inclusión del género en su agenda política como forma de socialización. Una de las primeras acciones, de cara a la comunidad internacional, fue la firma por parte de la monarquía saudí del tratado de la Convención sobre la Eliminación de Todas las Formas de Discriminación contra la Mujer (CEDAW) de las Naciones Unidas en el año 2000. En el año 2004, el género sería una de las temáticas fundamentales en el Tercer Encuentro para el Diálogo Nacional del King Abd Al Aziz Center of National Dialogue, pero éste se saldó de forma improductiva ${ }^{20}$.

En el año $201 \mathrm{I}$ una de las medidas más aplaudidas internacionalmente fue la de permitir el voto a las mujeres en las siguientes elecciones, que se celebrarían en 2015, a pesar de estar obligadas a ser acompañadas por un hombre de su familia y de las escasas garantías democráticas

\footnotetext{
17 MERINERO MARÍN, María José, Resistencia Creadora en Irán..., op.cit., pp. 17I-I72.

${ }^{18}$ FADAEE, Farshid, Iran and Saudi Arabia, and the Perfect Storm in the Persian Gulf, Uppsala University, Department of Peace and Conflict Research, 2017, pp. 16-17, 24-26. ROY, Josee, “Contemporary Women's Activism and Reform in Saudi Arabia”, CRSA:Concordia Religion Students' Association, Vol. I, 2015, p. 4.

19 MÉNORET, Pascal, Arabia Saudí: El reino de las ficciones, Bellaterra, Barcelona, 2003, p. $158-162$.

${ }^{20}$ ROY, Josee, “Contemporary Women's Activism”, CRSA Academic Journal of Religion, 2015, pp. 63-64.
} 
del estado ${ }^{21}$. En dichas elecciones, un I\% de los votos fueron para las candidatas ${ }^{22}$.

Otra de las principales medidas de la monarquía fue la de permitir la participación de 30 mujeres en el Consejo de la Shura siempre y cuando éstas tuvieran moralidad intachable ${ }^{23}$; todo en el contexto de un consejo que había permanecido inactivo desde 1926 y que fue reformado en el año 2000 como órgano de consulta sin carácter vinculante ${ }^{24}$.

Desde la toma de estas medidas la incorporación de políticas de género por parte de la monarquía saudí ha crecido exponencialmente, siendo las últimas medidas previas a la llegada de Muhammad Bin Salman una campaña contra la violencia machista en 2013 y la concesión de documentos de identidad para las mujeres. De la misma manera, en los medios de masas la presencia de mujeres ha aumentado notablemente, siempre con un discurso sesgado en tanto que, aunque el género es el gran debate en la sociedad saudí, las reformas siempre se hacen dentro de un espacio limitado por la propia monarquía ${ }^{25}$.

\section{b) Las reformas de Muhammad Bin Salman}

En la actualidad, el Reino de Arabia Saudí se encuentra en manos del heredero al trono, MBS, quien se ha consolidado en el poder mediante una nueva política basada en ganarse el favor de la juventud saudí - ya que el $70 \%$ de la población del país corresponde a menores de 30 años — así como de la opinión internacional a partir de la introducción de reformas sociales y económicas resumidas en el plan Vision203026. No obstante, desde su nombramiento a mediados de 2017, ha mantenido un férreo control del gobierno ${ }^{27} y$ una política regional beligerante hacia su vecino Irán, con quien mantiene rivalidades geopolíticas ${ }^{28}$. Desde junio de 2017,Arabia Saudí ha adquirido una política cuádruple:

- A nivel regional ha buscado llevar a Arabia Saudí de una forma mucho más activa que su predecesor a la hora de luchar por la hegemonía en Oriente Medio.

- A nivel nacional, ha aumentado notablemente la autoridad de la monarquía, buscando concentrar en su persona amplios poderes, especialmente tras detener en una misma noche a doscientos miembros de la élite política y económica saudí el 4 de noviembre de 2017.

- Diversificación económica mediante su plan Visión2030.

- Adopción de una "revolución desde arriba", basada en la adquisición de políticas de reforma controladas estrictamente por la monarquía, tales como permitir el cine o la música en directo, así como el inicio de una serie de reformas de género, como la permisión de la

\footnotetext{
21 MARTíN, Javier, La Casa de Saúd, Catarata, Madrid, 2013, p. 164.

${ }^{22}$ FREEDOM HOUSE, "Freedom House: Saudi Arabia Profile", 2017: https://freedomhouse.org/report/freedom-world/20I7/saudi-arabia [Consultado el 15 de agosto de 20I8].

${ }^{23}$ AL JAZEERA, "Saudi king names women to advisory council", 12 de enero de 2018 : https://www.aljazeera.com/news/middleeast/2013/0I/20I3 I I 23462426/97I.html [Consultado el 20 de agosto de 20 I8].

24 ROY, Josee, “Contemporary Women's Activism...” op.cit., p.64.

${ }^{25}$ LE RENARD,Amélie, “Only for Women:The State and Reform in Saudi Arabia”, en The Middle East Journal, Vol. 62, 2017, pp. 610-629.

${ }^{26}$ Vision2030 Official Webpage: http://vision2030.gov.sa/en [Consultado el 20 de agosto de 2018] GAUSE III, F. Gregory, "Fresh Prince: The Schemes and Dreams of Saudi Arabia's Next King", en Foreign Affairs, Mayo/Junio de 2018: https://www.foreignaffairs.com/articles/middleeast/2018-03-19/fresh-prince [Consultado el 17 de agosto de 2018]

27 Ibídem.

${ }^{28}$ GRUMET, Tali Rachel, New Middle East Cold War: Saudi Arabia and Iran's Rivalry, University of Denver, Denver, 2017, pp. I02, 103.
} 
conducción o del acceso a estadios deportivos a mujeres ${ }^{29}$.

A partir de lo anterior, la "revolución desde arriba" de MBS tiene la intención de legitimar sus acciones a nivel internacional ${ }^{30}$. Su principal logro habrá sido elevar el debate sobre la situación de las mujeres en Arabia Saudí al ámbito de lo doméstico y de lo internacional. Es por ello por lo que en los últimos años ya se ha venido labrando una creciente presencia del debate tanto en medios de comunicación como en lo académico.

Alanoud ${ }^{31}$ habla en su tesis de dos formas de percibir la identidad de género en Arabia Saudí: la primera es la construida a partir del discurso mainstream de las autoridades, el discurso moral de los clérigos wahabíes que controlan los medios de comunicación que hace a la mujer portadora de signos de identidad y orden islámicos, tanto para el mundo como para la nación saudí2; el segundo será el que las mujeres crean para sí a través de su agencia, que será tratado en el siguiente apartado.

Tomando como ejemplo algunas de las voces académicas que reflexionan desde las universidades del país, podemos resaltar la adopción del término "feminismo" en el discurso académico como una novedad, pero con amplios matices. La universidad Nora Bint Abd Al Rahman, la mayor universidad femenina del mundo, ha publicado diversos artículos en los últimos años al respecto, $y$ en ellos puede verse una constante alabanza a la adquisición de derechos políticos de las mujeres a través de la inclusión en el Consejo de la Shura o en la de la tarjeta de identidad, con una crítica muy suave a la segregación absoluta de género en todo el país ${ }^{33}$. Se aboga por la igualdad dentro de las instituciones, y la máxima reivindicación es la necesidad de un aumento de la inclusión de las mujeres en el sistema educativo y en el mundo laboral ya que, aunque hoy constituyen un $50 \%$ de la población universitaria, solo el $15 \%$ de las graduadas accede al mercado laboral. Las autoras Yahya Alhareth, Yasra Alhareth e Ibtisam Al Dighrir, pertenecientes al Ministerio de Educación saudí, mencionaron de forma superflua la problemática de la custodia masculina, pero su conclusión es nimia:"el estatus de las mujeres en la sociedad saudí debe ser mejorado tratándolas con más respeto y asegurando sus derechos como humanas, respetándolas para que tengan oportunidad de acabar su educación" ${ }^{34}$.

La incorporación del feminismo en los últimos años al debate político ha venido acompañada de la principal medida de Muhammad bin Salman:permitir a las mujeres saudíes conducir a partir de septiembre de 2017. Esta medida ha sido aplaudida por la comunidad internacional ${ }^{35}$, especialmente

29 GAUSE III, F. Gregory, “Fresh Prince:The Schemes and Dreams...”, op.cit. pp. 2-3.

30 HAYKEL, Bernard, “Transformation of Saudi Arabia: Can MBS's Economic and Religious Reforms Succeed?” en Princeton University, I9 de julio de 2018: https://www.youtube.com/watch?v=ma lkqF5elb8 [Consultado el I6 de agosto de 20I8].

31 ALOUFI,Alanoud, Gender and National Identity in Saudi Arabia, San Francisco State University, San Francisco, 2017, p. 66.

32 Debemos hacer referencia, de nuevo, a las tesis de Gillian Youngs (2004: 79) y de Sophie Bessis sobre la creación de una narrativa de “objetización” de las mujeres como "representante de la cultura”. BESSIS, Sophie, Les árabes, les femmes, la liberté, Alianza Editorial, Madrid, 2008, pp. 65, 66. YOUNGS, Gillian, "Feminist International Relations: a contradiction in terms? Or: why women and gender are essential to understand the world 'we' live in”, en International Feminist Journal of Politics / International Affairs, Vol. I, 2004, p. 79.

33 SALEH AL KHAMSI, Sarah,ABUD-ALAZIZAL KHIELFE, Shorook, "Feminist Movement Obstacles in Saudi Arabia”, en Journal of Social Sciences of Princess Nora Bint Abdulrahman University, 2016, p.96.

${ }^{34}$ ALHARETH,Yahya,ALHARETH,Yasra,AL DIGHRIR, Ibtisam, "Review of Women and Society in Saudi Arabia”, en American Journal of Educational Research, 2015 , p. 7.

35 THE ECONOMIST, "At last Saudi women will be allowed to take the wheel”, 30 de septiembre de 2017 : 
por diarios occidentales que han seguido en los últimos años la campaña Women2Drive. La presión internacional, llevada a cabo desde 2008, cumplió de forma muy exacta el ciclo de la norma de Finnemore y Sikkink, a pesar de que, con la inclusión de la norma, el estado saudí ha adquirido el título de "estado reformista", y MBS el de "monarca progresista" ${ }^{6637}$, desviando la atención pública tanto de los crecientes abusos a los Derechos Humanos de la monarquía saudí como de las demandas de los movimientos feministas.

\section{c) Género y emprendimiento normativo en Arabia Saudí}

El director del principal Think Tank de Arabia Saudí,Alí Shibabi, de Arabic Foundation, ha sido uno de los principales defensores intelectuales de permitir a las mujeres saudíes conducir, argumentando dos razones: la posibilidad de que las mujeres saudíes puedan conducir implicaría un impacto económico positivo en la diversificación económica gracias a un crecimiento en el acceso de las mujeres al trabajo. De la misma manera, el autor resalta los riesgos que para MBS suponen semejantes reformas, ya que lo enfrentan a los sectores más conservadores de la sociedad saudi ${ }^{38}$.

Sin embargo, entre septiembre de 2017 y julio de 2018, siete activistas por los Derechos de las Mujeres fueron detenidas, habiendo participado cinco de ellas directamente en las campañas por la legalización de la conducción para las mujeres ${ }^{39}$. Según la analista Hana Al-Khamri, autora de Female Journalists in Gender-Apartheid Saudi Arabia, el gobierno saudí comunicó a las principales activistas que permanecieran en silencio y que desactivaran sus cuentas de Twitter el mismo día en el que anunció la legalización de la conducción. Las dos principales activistas por el derecho a la conducción,Aziza al-Youssef y Loujain al-Hathoul, hoy detenidas, también se han opuesto a lo que los grupos feministas saudíes han considerado el principal problema de Arabia Saudí: la custodia masculina ${ }^{40}$. La custodia masculina es el sistema que fundamenta lo que la totalidad de activistas saudíes como Al-Youssef,Al-Hathoul o la propia Al-Khamri, han determinado como "apartheid de género", basado en que todas las mujeres deben tener un hombre guardián con la autoridad para tomar decisiones por ellas, y por el que las mujeres deben recibir el permiso para tener pasaporte, viajar fuera del país, estudiar, casarse, salir de prisión o, actualmente, conducir ${ }^{41}$.

Podemos ver que la estrategia del gobierno saudí se ha basado en adquirir el papel de reformista, cediendo ante la presión doméstica e internacional con el objetivo de permitir el acceso de las mujeres a la esfera pública, pero limitándolo a partir del encarcelamiento inmediato

https://www.economist.com/leaders/2017/09/30/at-last-saudi-women-will-be-allowed-to-take-the-wheel [Consultado el 20 de agosto de 2018]

${ }^{36}$ JOHNSON, Boris, “Saudi Reformer Mohammed Bin Salman Deserves Our Support”, en The Times, 28 de febrero de 20I8: https://www. thetimes.co.uk/article/boris-johnson-saudi-reformer-mohammed-bin-salman-deserves-our-support-k5lhkhqlh [Consultado el 05 de Abril de 2018

37 FRIEDMAN, Thomas L., "Saudi Arabia’s Arab Spring, at Last", en The New York Times, 23 de Noviembre de 2017: https://www.nytimes. com/2017/II/23/opinion/saudi-prince-mbs-arab-spring.html [Consultado el I6 de agosto de 20I8]

38 SHIBABI, Ali, "Ali Shibabi discusses the end of Saudi Arabia's ban on women driving with bloomberg", en Arabia Foundation, 29 de marzo de 2018: http://www.arabiafoundation.org/videos/ali-shihabi-discusses-the-end-of-saudi-arabias-ban-on-women-driving-with-bloomberg/ [Consultado el 20 de agosto de 2018]

39 THE FINANCIAL TIMES, “Saudi Arabia arrests campaigners who challenged women driving ban”, I8 de mayo de 20I8: https://www.ft.com/ content/bfcdfcfc-5aa7-I le8-bdb7-f6677d2elce8 [Consultado el 26 de agosto de 2018]

40 AL-KHAMRI, Hana, “Why did Saudi Arabia lift the driving ban on women only now?, en Al Jazeera, 24 de junio de 2018 : https://www.aljazeera. com/indepth/opinion/saudi-arabia-lift-driving-ban-women-I8062I203632446.html [Consultado el 19 de agosto de 20I8]

41 Human Rights Watch "Saudi Arabia: End Male Guardianship”: https://www.hrw.org/endmaleguardianship [Consultado el 2I de agosto de 2018] 
de las emprendedoras normativas. La nueva ley sobre la conducción manifiesta una tensión entre la modernización hacia la diversificación de la economía a la que Arabia Saudí quiere enfrentarse bajo el plan Vision2030, para la cual es necesaria la capitalización del género, al mismo tiempo que se enfrenta a un sistema patriarcal que busca la explotación y confinación de las mujeres en lo doméstico ${ }^{42}$.

La gran brecha que existe entre los movimientos sociales y las élites en Arabia Saudí, lejos de haberse estrechado con las nuevas leyes, ha aumentado, en tanto que la apropiación del discurso y de las demandas de éstas por parte del gobierno busca dejarlas sin voz tanto en lo doméstico como en lo internacional.

A pesar de ello, los diferentes cambios socioeconómicos de Arabia Saudí han permitido abrir vías y espacios de debate en los que las mujeres saudíes han podido ejercer el activismo para establecer sus demandas, las cuales se alejan mucho de la legalización de la conducción. A pesar de la falta de impacto cualitativo de las reformas - al menos a corto plazo-, la inclusión de las mujeres en la esfera pública ha aumentado a partir de su presencia en organismos políticos, en medios de comunicación y en el mercado laboral. Si el férreo control de la opinión pública de un gobierno paternalista en extremo con las mujeres no ha permitido la transmisión de sus demandas, la puesta de las redes sociales al alcance de las saudíes ha sido una clave para el aumento de la agencia por sus derechos $y$, principalmente, contra todo el sistema de la custodia masculina. Las redes sociales se han convertido en plataformas de expresión y de empoderamiento, en tanto que, a través de ellas, son capaces de intercambiar experiencias y opiniones sobre las formas de opresión del sistema saudí ${ }^{43}$. Activistas como Hala Al Dorsari, activista online, se dedican a ayudar a mujeres que sufren violencia machista a partir de asesoramiento legal y psicológico ${ }^{44}$. La transgresión social que implica la demanda de derechos a partir de las redes sociales supone la principal plataforma a través de la cual las mujeres demandan de forma doméstica e internacional la abolición del sistema de custodia masculina. Gracias a esto, las mujeres saudíes han podido llevar a debate no la aplicación de medidas liberales y en gran parte patrocinadas por Occidente, como la permisión de la conducción, sino a la apropiación de la religión y al cuestionamiento de las bases del wahabismo, buscando el desarrollo personal y la legitimación de la igualdad de género a partir de la separación de aquello que es puramente islámico y aquello que es neotradicional, deconstruyendo la identidad patriarcal saudí impuesta a partir de la segregación de género y de la "revolución desde arriba" 4546.

\section{La rivalidad entre Arabia Saudí e Irán como factor determinante de la incorpora- ción de políticas de género}

Si bien es necesario contextualizar las relaciones entre los dos estados, el objetivo de este apartado

\footnotetext{
${ }^{42} \mathrm{La}$ incorporación de estas medidas implica un debate entre capitalismo y patriarcado que tanto Walby como Tickner han descrito. Walby describe el debate entre ambos por la explotación de las mujeres entre lo público y lo doméstico, mientras que Tickner especifica cómo la identidad de un estado y las medidas de éste se construyen de forma patriarcal, condicionando una jerarquía de género que fundamenta esa economía de explotación y la segregación. WALBY, Sylvia, Theorizing Patriarchy, Basil Blackwell, Oxford, I990. TICKNER, J.Ann, “What Is Your Research Program? Some Feminist Answers to International Methodological Questions” en Interntional Studies Quarterly, Vol. 49, 2005, pp. I9.

43 ALOUFI,Alanoud, Gender and National Identity..., op.cit, pp. I00-102.

44 ROY, Josee, “Contemporary Women's Activism”..., op.cit., pp. 63-68.

45 ALOUFI,Alanoud, Gender and National Identity..., op.cit., pp. 66-68.

46 LE RENARD, Amélie, "Personal Development and the "Rights of Woman”: Women's Appropiation of Religion in Saudi Arabia”, en SciencesPo, PP. 14-17.
} 
es resaltar cómo ambos han reconstruido sus identidades de forma polarizada a partir de la década de 1980. Esto es fundamental para comprender cómo hoy esa rivalidad ha condicionado la adquisición de unas políticas de género que han tenido unas determinadas implicaciones a nivel regional y a nivel internacional, las cuales procederemos a describir de forma somera.

Desde 20II, tras las revueltas en el mundo árabe, la relación entre ambos estados ha empeorado a causa de un cambio en la política regional e internacional saudí. Este cambio vendrá de la mano de la renovación de la relación con Estados Unidos, una alianza que se desarrollará en gran parte desde el acceso de MBS al poder en Arabia Saudí y del triunfo de Donald Trump en las elecciones estadounidenses. Desde 201 I la política regional saudí ha adquirido un papel mucho más activo que en cualquier momento anterior, buscando convertirse en un actor hegemónico en detrimento de Irán alineando su posición beligerante hacia éste con la Administración Trump en la actualidad. Este alineamiento viene de la mano de una serie de políticas que han causado, primero, la inclusión de forma más activa de Arabia Saudí en conflictos que se estaban desarrollando en la región, tales como Siria, Líbano o Palestina, así como abriendo nuevos frentes en Yemen o en Qatar $^{47}$.

La creciente hostilidad estadounidense hacia Irán a través de acciones como de la cancelación del pacto por el programa nuclear iraní o JCPOA (Joint Comprenhensive Plan of Action) y de la imposición de múltiples sanciones económicas han condicionado notablemente las respuestas diplomáticas de Irán a los intereses hegemónicos saudíes, convirtiéndose la rivalidad entre ambos estados y la injerencia en ésta de Estados Unidos el principal factor de desestabilización regional ${ }^{48}$.

\section{I. Reconstruyendo identidades: la polarización de las identidades saudí e iraní en el contexto de la rivalidad regional}

Desde la revolución iraní de 1979 y desde el inicio de las políticas conservadoras saudíes de 1980 se ha procedido a una polarización regional que ha contribuido a que ambos estados se perciban mutuamente desde la hostilidad. La hostilidad geopolítica la ha condicionado la construcción de dos identidades nacionales que se han expandido de lo político a lo religioso y cultural en pro de legitimar los intereses de ambos estados ${ }^{49}$. Según Przemysław Osiewicz se han ido construyendo dos identidades contrapuestas a partir de: la experiencia histórica, la actitud de la sociedad hacia el poder, la legitimidad del poder, la relación con respecto a la totalidad de la comunidad islámica, los objetivos políticos puntuales y la jerarquía social y su organización ${ }^{50}$.

\section{Como afirma Shokrollah Kamari Majin:}

"La identidad de una nación puede ser considerada como un factor de cohesión y unión nacional pero también como un factor de diferenciación con respecto a otros. A la hora de examinar las relaciones políticas dentro del marco nacional, las esferas de poder principales que compiten para ganar más poder e influencia

\footnotetext{
47 AHMADIAN, Hassan, “How effective is Saudi Araba's 'Counter-Iran Policy'?", AlSharq Forum Analyis, 2017 , p. 9.

48 Ibídem, p. 9.

49 MAJIN, Sokrollah Kamari, “Iranian and Saudi Cultural and Religious Identities: Constructivist Perspective”, en Open Journal of Political Science, 7, 2017, p. 65.

50 OSIEWICZ, Przemysław, “Ideological Determinants of the Current Saudi-Iranian Rivalry in the Middle East”, en Poznan University, Poznan, 20I6, pp. I I5-I I6.
} 
también necesitan de ideas, valores básicos, objetivos y reivindicaciones atractivas para el pueblo. Las relaciones de poder, entonces, siempre se encuentran bajo la superficie de la actividad cultural"'5!.

La construcción de la identidad nacional es necesaria para comprender la rivalidad entre ambos estados, en tanto que "las identidades de los estados determinan sus políticas externas", y la identidad se construye en relación con la propia historia y cultura, así como en relación con otras identidades. Las dos identidades nacionales se han desarrollado en las últimas décadas en contraposición, lo que puede resumirse en cuatro factores relacionados con las claves de Osiewicz. Arabia Saudí tiene como componentes básicos de su identidad su etnicidad árabe, su situación como guardianes de los Santos Lugares del islam, Meca y Medina, el hipotético liderazgo de la comunidad musulmana suní y la prédica de la doctrina wahabí dentro de esta rama; el sistema monárquico absoluto; y la economía basada únicamente en el petróleo. Por otro lado, Irán basa su identidad en su etnia persa, el chiísmo como clave del poder político y religioso y la legitimación del Velayat-e Faqih así como de la expansión de la revolución islámica; el sistema de república islámica, y el petróleo como base económica ${ }^{52}$.

"En Oriente Medio la identidad se ha expresado en la religión que, de hecho, significa comunidad"53. A la hora de describir la identidad saudí debemos detenernos en cuatro debates basados en contradicciones que han constituido la identidad nacional actual, todos relacionados con la religión. El primero de ellos es la presencia de una tradición vernácula, con fuerte influencia preislámica y que, lejos de desaparecer, parece confundirse con lo propiamente islámico, con fenómenos como los códigos - y crímenes- de honor. En relación con esto está la "tradición reinventada, órgano de propaganda confeccionado por el régimen, tradición "nacional" con resabios a veces folclóricos". En tercer lugar, el debate entre la modernidad social y económica atribuida al islam a pesar de ser completamente inédito, como "el estatuto de la mujer"; y en cuarto lugar la ambigüedad del término islam, usado en múltiples contextos tanto para justificar la tradición como la modernidad ${ }^{54}$.

Desde la década de 1970, especialmente tras la crisis de 1973, Arabia Saudí ha sufrido un boom económico relacionado con la producción petrolífera acompañado de mutaciones económicas y sociales. Sin embargo, con el proceso económico no ha habido un progreso social proporcional,sino que la riqueza sirvió para perpetuar la tradición en una progresiva anacronización de las tradiciones. El desarrollo económico dio lugar a un acelerado proceso de urbanización y de atomización familiar que desvinculó al individuo de las organizaciones familiares tradicionales. El vertiginoso aumento del nivel de vida llevó a una relectura de la tradición, acompañada de un discurso religioso wahabí que rechaza la innovación y la modernidad ha dado lugar a "estructuras sociales inéditas", muchas de las cuales legitiman la segregación de género y normalizan prácticas antes poco extendidas como la poligamia. La sociedad saudí, bajo los dictados de la Casa de Saúd y los cambios socioeconómicos vividos entre 1980 y 2005 en los que el país se ha urbanizado, las familias se han atomizado y el número de jóvenes e inmigrantes ha crecido, ha sufrido una

\footnotetext{
51 MAJIN, Sokrollah Kamari, “Iranian and Saudi Cultural and Religious Identities...”, op.cit, p. 62.

52 Ibídem. p. 67

53 MERINERO MARTÍN, María José, Irán: hacia un desorden prometedor..., op.cit., p. 38.

54 MÉNORET, Pascal, Arabia Saudí: El reino..., op.cit., p. 194.
} 
modernización superficial y ambigua, reinventando las tradiciones ${ }^{55}$ a partir de las lecturas del wahabismo en un proceso de reconstrucción identitaria basado en:"releer" la historia,"reinventar" la tradición y "manipular" la herencia ${ }^{56}$.

La identidad nunca es monolítica, sino algo que fluye, que se construye, deconstruye y reconstruye periódicamente. La identidad iraní se centra en lo persa, como etnia y como vínculo lingüístico — de la misma forma que el árabe para los árabes en Arabia Saudí-, pero también a una adscripción territorial e histórica. A esto, de forma progresiva a lo largo de la historia, se le ha añadido la identidad chií, que ha proporcionado un carácter religioso a la identidad iraní. Al conseguir el clero chií convertirse en autoridad temporal más allá de lo espiritual a través de la Revolución Islámica, la identidad religiosa chií se ha ligado a la identidad cultural y política iraní ${ }^{57}$.

El lema de la revolución islámica de 1979 fue "ni Oriente, ni Occidente”, y caracteriza la política de rechazo hacia lo occidental que ha seguido el país hasta la actualidad, en la que el no alineamiento ha venido de la mano de la creación de un tradicionalismo ligado a la politización de la religión como modelo de organización política ${ }^{58}$. La identidad político-religiosa iraní, desde entonces, se ha marcado tanto por el rechazo hacia lo occidental, reacción a las políticas modernizadoras del Shah y a las injerencias occidentales, como por la aplicación de la filosofía islámica a las relaciones internacionales. La expansión de la revolución, la unidad nacional y la justicia social a partir de los preceptos islámicos forman también parte de esta identidad ${ }^{59}$.A esto se le añade el principio identitario de "democracia religiosa", que si bien está sujeto al Velayat-e Faqih, liga a la sociedad civil el principio de "revolución constante" o de "agencia colectiva", que tanta relevancia tendrá en las relaciones de poder que trataremos posteriormente ${ }^{60}$.

La constitución de identidades divergentes desde la década de 1980 ha legitimado la hostilidad entre ambos estados. A partir de la construcción de una identidad política ligada a la religión se ha procedido a percibir al otro como una amenaza para la seguridad regional y para los intereses nacionales; ambos estados se perciben mutuamente como enemigos ideológicos. La retórica islámica se ha usado para legitimar domésticamente cada régimen y para denominar al enemigo, discurso adoptado por las élites de ambos estados que tiene como máxima expresión la contraposición del Líder Supremo de la Ummah o Comunidad Islámica - hoy el Ayatollah Alí Jamenei- con el Guardián de las Dos Mezquitas Sagradas.

La mutua percepción como problema de seguridad regional y la escalada de las tensiones por una rivalidad económica y geopolítica aumentó durante el gobierno de Mahmoud Ahmadineyad, con el desarrollo del programa nuclear, saldándose con una pérdida de la tolerancia mutua con el discurso religioso como superficie de un conflicto de intereses directamente relacionados con la entrada en una etapa en la que ambos estados han procedido a la "socialización internacional".

\footnotetext{
55 Con la "invención de las tradiciones" nos referimos al término de Eric Hobsbawm y Terence Ranger, referido a aquellas tradiciones que son creadas con el objetivo de legitimar nacionalismos o prácticas culturales. HOBSBAWM, Eric, RANGER, Terence, The invention of tradition, Cambridge University Press, Cambridge, 1983.

56 MÉNORET, Pascal, Arabia Saudí..., op.cit, pp. 209-2 10.

57 MERINERO MARTÍN, María José, Irán: hacia un desorden..., op.cit., p. 39.

58 MAJIN, Sokrollah Kamari, “Iranian and Saudi Cultural and Religious Identities...”, op.cit., p.69.

59 OSIEWICZ, Przemysław, “Ideological Determinants of the Current Saudi-Iranian Rivalry...”, op.cit., p. I20.

60 McCALL, Corey, COLLEGE, Elmira, “Ambivalent Modernities...”, op.cit., p. $4 \mathrm{I}$.
} 
En el contexto de un desarrollo, primero iraní y, en los últimos años saudí, de una política de injerencia en terceros países a escala regional, así como una competencia en el mercado del petróleo ha tenido como consecuencia el surgimiento de la necesidad de legitimarse a nivel internacional como líderes regionales. Las palabras de Majin definen el giro de las políticas de ambos estados en la última década:

"En un mundo en el que las arenas de lo político y lo ideológico están más separadas que nunca, es más y más urgente para un estado cuya misión principal es promover una religión ser aceptado como un miembro respetable de la comunidad internacional"6l.

El proceso de "socialización internacional" que ambos estados han desarrollado especialmente tras las revueltas árabes de $20 \mathrm{II}$ ha planteado una nueva arena: el reformismo y la incorporación de políticas de género como parte de una nueva identidad estatal e internacional.

\subsection{La incorporación de políticas de género como modelo de legitimación del lide- razgo regional}

Desde la llegada al poder del rey Salman bin Abd al Aziz y, especialmente, de Muhammad bin Salman, los intereses por la hegemonía regional de Arabia Saudí se han mostrado en aumento, chocando con la tradición de expansión de la revolución de Irán. Partiendo de esta rivalidad identitaria debemos detenernos en el surgimiento de la necesidad de ambos estados de legitimar sus crecientes intereses de convertirse en la única potencia de Oriente Medio desbancando a la otra. Esta legitimidad no procede únicamente de un discurso doméstico - la construcción de la identidad que hemos visto en puntos anteriores - o regional - la defensa como cabezas de las comunidades musulmanas-, sino también a escala internacional. Ambos estados han accedido a un proceso de "socialización internacional" que, si bien en Irán se ha guiado desde su visión islámica de las relaciones internacionales, Arabia Saudí ha accedido a un cambio de paradigma.

Este cambio, manifestado en un crecimiento exponencial en su actividad regional, se basa en la legitimación de dichas acciones a partir de una entrada en un proceso de modernización dirigida, que ha abierto procesos de cooperación bilateral con Occidente $y$, especialmente, con Washington, desde la llegada de Donald Trump al poder y de su manifiesta hostilidad hacia Irán ${ }^{62}$. Si la nueva política de modernización saudí como parte de la socialización ha venido de la mano de una serie de reformas que veremos posteriormente, ésta ha seguido el mismo esquema que define Pascal Ménoret a la hora de describir la trayectoria de Arabia Saudí en las últimas décadas: potenciación de la sociedad urbana y centralización del estado, mantenimiento de los aparatos de represión, deformación de la tradición e introducción de políticas de modernización "desde arriba"63.

El actual proceso de modernización saudí para la legitimación de su rivalidad con Irán tiene su máxima expresión en la inclusión de políticas de género en su agenda internacional. La construcción de una nueva identidad nacional de género será la nueva arena en la que Arabia Saudí disputará a Irán la legitimidad como potencia regional ante la comunidad internacional, para lo cual ha adaptado de forma precisa el modelo del "ciclo de la norma" de Martha Finnemore y

\footnotetext{
61 MAJIN, Sokrollah Kamari, “Iranian and Saudi Cultural and Religious Identities...”, op.cit., p. 79.

62 AHMADIAN, Hassan, "How effective is Saudi Arabia's...", op.cit, pp. 5-6.

63 MÉNORET, Pascal, Arabia Saudí: El reino..., op.cit., p.l 93.
} 
Kathryn Sikkink, mediante una apropiación, no obstante, del discurso de las activistas. Las fuertes violaciones de los derechos de las mujeres en Arabia Saudí, cuyo puesto en el Gender Gap Report de 2016 delWorld Economic Forum la sitúa en el puesto número I 44 de $146^{64}$ ha condicionado la necesidad de incorporación de políticas de género de Arabia Saudí en el proceso de "socialización internacional", pasando por la "institucionalización" de las medidas al mismo tiempo que, siguiendo los procesos de socialización de Kenneth Waltz, "emula" a las potencias internacionales bajo las presiones de éstas, "alabando" a los estados entre los que se incluye a la hora de adquirir políticas de género y "ridiculiza" a estados que no cumplen con este proceso. En este proceso de ridiculización, Arabia Saudí ha encontrado el espacio para ridiculizar a Irán ${ }^{65}$, al mismo tiempo que se reafirma en la incorporación de políticas de género y construye una identidad en base a la agenda internacional. Por ello, mientras que la identidad nacional saudí se compone de una serie de factores religiosos, políticos, económicos y sociales que han construido la narrativa que hemos analizado, el papel del género como factor identitario ha aumentado ${ }^{66}$, confirmando las tesis de Youngs y de Bessis en cuanto a la objetización de la mujer como modelo de dominación.

Como hemos podido ver en el cuarto punto, la República Islámica de Irán ha venido aquiriendo una trayectoria de incorporación del género a su agenda muy distinta. Si bien es cierto que la trayectoria parece haber sido acelerada por la rivalidad, también es necesario resaltar que las dinámicas de poder iraníes han favorecido a la ubicación de dichas medidas en el contexto de las demandas de los movimientos sociales iraníes.

En Arabia Saudí, la Casa Real ostenta el poder a partir de un sistema autoritario, debatiéndose constantemente con el conservadurismo wahabí, que legitima el poder saudí y que tiene como objetivo la expansión de su modelo islámico ultraconservador. Sin embargo, es la comunidad internacional y EEUU en particular quienes legitiman el papel regional saudí, habiendo una constante tensión entre el poder interno (saudí-wahabí) y externo (comunidad internacionalmonarquía saudi) ${ }^{67}$. A la hora de crear una identidad nacional de género ambos estados han accedido, de una forma u otra, al "gender mainstreaming”. Sin embargo, en Irán, comparativamente, en el ciclo de la norma intervienen los movimientos sociales de mujeres como emprendedores normativos, mientras que en Arabia Saudí lo determinante para la adquisición de políticas de género es lo global y dichas tensiones entre poderes internos y externos. De esta manera $y$, como se ha visto en los puntos anteriores, las reformas saudíes tienen el doble papel de reducir la autonomía de los movimientos sociales feministas encabezando la reforma y participando del emprendimiento normativo al mismo tiempo que responden a las presiones en el contexto de socialización internacional. Por el contrario, en Irán las reformas son concesiones que se consiguen de forma muy lenta con la constante actividad de movimientos sociopolíticos, tendiéndose a una armonización de las tensiones domésticas del gobierno islámico con los reformistas mientras se incluyen en el proceso de socialización internacional.

\footnotetext{
64 WORLD ECONOMIC FORUM, “Global Gender Gap Report”, 2016: http://reports.weforum.org/global-gender-gap-report-0I6/ economies/?doing_wP_cron=|5350203 |5.007503986358642578|250\#economy=SAU [Consultado el I6 de agosto de 20 I8]

65 GOLDBERG, Jeffrey, “Crown Prince: Iran's Supreme Leader 'Makes Hitler Look Good”, en The Atlantic, 2 de abril de 2018 : https://www. theatlantic.com/international/archive/2018/04/mohammed-bin-salman-iran-israel/557036 [Consultado el 08 de agosto de 2018]

66 ALOUFI,Alanoud, Gender and National Identity..., op.cit., p. 93.

${ }^{67}$ MAJIN, Sokrollah Kamari,“Iranian and Saudi Cultural and Religious Identities...”, op.cit., pp. 75-76.
} 


\section{La rivalidad y la inclusión del género en la agenda de ambos estados en el contexto internacional: implicaciones}

La recepción en Occidente con respecto a la política deArabia Saudí e Irán ha sido muy diferenciada. La guerra en Yemen, el bloqueo de Qatar, y el creciente poder autoritario del nuevo heredero al trono parecen haber sido eclipsados por sus medidas reformistas, a pesar de la ausencia de cualquier intención de reforma democrática. La narrativa en torno a MBS como un monarca reformista y revolucionario ha tenido un efecto muy positivo en las relaciones con España, Reino Unido o Estados Unidos.

En febrero de 2017, Ramsi Jazmati, del Instituto Choiseul, publicó un artículo en la revista del Instituto Español de Estudios Estratégicos en el que planteaba a Arabia Saudí como un "aliado imprescindible para Europa y para España" y en el que, en el contexto de la rivalidad con Irán, Ilama a aumentar y mejorar las relaciones bilaterales con el reino árabe en apoyo a la implementación del plan Vision2030. Entre muchos otros aspectos, el autor justifica su recomendación en las políticas de género saudíes, que pretenden aumentar la participación de las mujeres en la fuerza laboral del $22 \%$ al $30 \%{ }^{68}$. En diciembre de 2017 , la periodista Beatriz Yubero Parro, en la misma revista e incluyendo a Irán en el mismo contexto de rivalidad con Arabia Saudí y con Estados Unidos, resaltó la desigualdad de género y las violaciones de derechos humanos como claves del enfriamiento de las relaciones españolas y europeas con el país ${ }^{69}$. Podemos ver una cristalización de este discurso favorable a Arabia Saudí y detractor de Irán en el comunicado de la Moncloa del 12 de Abril de $2018^{70}$, en el que se resalta el papel humanitario saudí en Yemen ${ }^{71}$ y la legitimación de la injerencia internacional de éstos en el contexto de la rivalidad con Irán ${ }^{72}$.

En el caso de Reino Unido, con la visita de Muhammad bin Salman a Theresa May en Abril de 2018, la opinión pública se mostró escéptica con él, siendo la prensa conservadora especialmente favorable a sus reformas. El mejor ejemplo es el del artículo de Boris Johnson, Saudi reformer Mohammed bin Salman deserves our support, donde el miembro del Partido Conservador aboga por el aumento de las relaciones bilaterales en apoyo al plan Vision2030, argumentando el papel del monarca saudí como defensor de los derechos de las mujeres ${ }^{73}$.

En Estados Unidos la reacción a las reformas saudíes ha tenido mucha más relevancia, pues no sólo se han potenciado las relaciones bilaterales, sino que se ha producido una alineación estratégica contra la República Islámica de Irán. El apoyo generalizado de la opinión pública, siendo uno de los artículos más representativos Saudi Arabia's Arab Spring, at Last, de Thomas L. Friedman,

${ }^{68}$ JAZMATI, Ramsi, “Arabia Saudí: aliado imprescindible para Europa y España”, en Instituto Español de Estudios Estratégicos, I6 de febrero de 20 I 7 , p. 20.

69 YUBERO PARRO, Beatriz, “Irán en la era de la Administración Trump” en Documento MARCO; Instituto Español de Estudios Estratégicos, I8 de diciembre de 2017 , p.37.

70 LA MONCLOA, “El presidente del Gobierno recibe al príncipe heredero de Arabia Saudi”, I2 de abril de 20I8: https://www.lamoncloa.gob. es/presidente/actividades/Paginas/2018/I204/8-visitaarabia.aspx [Consultado el 25 de agosto de 20I8]

71 “España tomó nota del plan integral saudí en favor de la población yemení, que tanto en Reino de Arabia Saudí como los Emiratos Árabes Unidos financiaron con mil millones de dólares en concepto de ayuda humanitaria”. Ibídem.

72 "Los dos países también enfatizaron la importancia de la adhesión a Irán al principio de la buena vecindad y no injerencia en asuntos internos de terceros países y de abstenerse de brindar cualquier apoyo a milicias terroristas. Ambas partes pidieron que Irán acate las resoluciones internacionales relacionadas con misiles balísticos y destacaron la importancia de evitar que Irán tenga armas nucleares”. Ibíd.

73 JOHNSON, Boris, "Saudi Reformer Mohammed Bin Salman...”, op.cit. 
define de forma excelente el carácter optimista hacia las reformas ${ }^{74}$. La influencia económica de Arabia Saudí en Estados Unidos a partir de la fundación de agencias de relaciones públicas y grupos de lobbying como BGR, Squire Patton Boggs o Hogan Lovells ha tenido un papel clave en la mejora de las relaciones entre ambos estados y de la imagen de MBS en EEUU, especialmente con la creación del grupo de lobby, SAPRAC ${ }^{75}$, el Saudi American Public Relation Affairs Committee. Kareem Chehayeb, de Amnistía Internacional, habla de que la "revolución desde arriba" busca ganarse la opinión internacional a la vez que evita el desarrollo de ONGs y grupos defensores de los Derechos Humanos, en tanto que la relación de las medidas de MBS con la libertad de expresión o asociación, ausente en Arabia Saudí, es nula ${ }^{76}$.

Las repercusiones de las medidas de Irán han sido mucho menores a causa de que las dinámicas de reforma han respondido a una dinámica interna y no externa. Mientras que Arabia Saudí se ha apropiado del discurso de los movimientos sociales manipulando el "ciclo de la norma" a partir de la intensificación de su actividad diplomática y del lobbying, Irán ha centrado sus esfuerzos en mantener el ahora débil JCPOA. Al mismo tiempo ha defendido su política de injerencia regional ante la hostilidad estadounidense, con escasas energías para hacer frente a la campaña de desprestigio internacional llevada a cabo por los saudíes ${ }^{77}$ basada en lo que Waltz denominó la fase de "ridiculización" en la socialización internacional.

El continuo aumento de la imposición de sanciones internacionales a Irán y la pragmática campaña internacional del príncipe saudí ha llevado a la República Islámica a un punto de inflexión en su política internacional. La tensión en Oriente Medio a causa de la rivalidad entre los dos estados parece aumentar a pesar de que Occidente ya haya otorgado la legitimidad como monarca reformista y defensor de sus intereses en la región a MBS.

\section{4. ¿Cuáles son los factores explicativos de la incorporación de cuestiones de género a la política internacional de Arabia Saudí e Irán?}

Para responder a la pregunta en la cual se basa el presente escrito se ha procedido al uso de las teorías constructivistas y de los estudios feministas de las Relaciones Internacionales para la definición de los múltiples factores que han condicionado la adopción de estas medidas. Se ha procedido al análisis a partir de tres ámbitos: lo internacional, lo doméstico y lo regional.

A la hora de analizar lo internacional, el primer factor ha sido la internacionalización de la agenda de género, que ha condicionado la entrada de los dos estados en un proceso de socialización bajo el cual han procedido a adoptar estas medidas. En lo doméstico, el factor determinante han sido las luchas de los movimientos sociales, si bien en Arabia Saudí éstas han sido silenciadas y su discurso apropiado por la monarquía mientras que, en Irán, las medidas han sido más modestas, pero han respondido a las demandas de dichos movimientos sociales, integrados en las dinámicas de poder.

\footnotetext{
74 FRIEDMAN, Thomas L., "Saudi Arabia's Arab Spring...”, op.cit.

75 SAPRAC,Saudi American Public Relation Affairs Committee: http://www.saprac.org/ [Consultado el 25 de agosto de 2018]

${ }^{76}$ AL JAZEERA, “Saudi Arabia 'seeks death penalty' for female activist”, 22 de agosto de 2018 : https://www.aljazeera.com/news/2018/08/saudi-arabia-seeks-death-penalty-female-activist-180822III93388I.html [Consultado el 25 de agosto de 2018]

77 AHMADIAN, Hassan, “How effective is Saudi...", op.cit, p. 9.
} 
En el caso de lo regional, el factor determinante ha sido la rivalidad entre ambos estados. Aunque la rivalidad tiene origen en la década de 1980, ha sido el interés de Arabia Saudí de legitimarse como principal aliado estratégico de Occidente y socio comercial en la región aumentando su política hostil hacia Irán la clave de la adopción de estas medidas. En el contexto de esta rivalidad, ambos estados han legitimado históricamente su enfrentamiento a partir de la construcción de identidades opuestas, identidades en las cuales las políticas de género juegan un papel determinante a la hora de definir su inclusión en la comunidad internacional.

En Arabia Saudí, las medidas han venido acompañadas de un interés, el de legitimarse a nivel internacional, el de defender su hegemonía a nivel regional y el de construir la imagen de MBS como "monarca reformista" a nivel doméstico e internacional. En el caso iraní, las medidas han tenido una trayectoria histórica mucho mayor y se han basado en un proceso a largo plazo de revolución constante y colectiva en la que las mujeres han participado de forma activa y cuya agencia ha resultado en el desarrollo de múltiples estrategias de acción y resistencia frente a una autoridad patriarcal. De esta manera, Irán ha accedido a una aceleración de ciertas reformas como parte de ese proceso de socialización a nivel internacional y de rivalidad, pero también como respuesta a sus dinámicas internas en relación con los movimientos feministas.

\section{Conclusiones}

El principal objetivo del presente escrito ha sido el de estudiar los factores por los cuales Arabia Saudí e Irán han desarrollado una serie de políticas de género comprendiendo las distintas dimensiones de estas. El carácter multifactorial de estas causas ha llevado a una conclusión que incluye lo internacional, lo doméstico y lo regional. La necesidad del estudio de estos factores desde una perspectiva crítica y de género ha demostrado ser de absoluta necesidad en tanto a la vigencia de dichas políticas.

La trayectoria de las reformas en Irán ha mostrado unas relaciones de poder y contrapoder que se deben tener en cuenta a la hora de considerar la situación de las mujeres, en tanto que, a pesar del carácter patriarcal y autoritario del estado, las estrategias de lucha y reivindicación de los movimientos feministas y la riqueza del debate deben reconocerse como parte de una dinámica histórica y social. Esta dinámica ha hecho que las medidas adoptadas por Irán tengan un largo recorrido histórico al mismo tiempo que responden a una dinámica interna, si bien la internacionalización de la agenda de género es un factor determinante.

La trayectoria saudí se ha visto influenciada en mucha mayor manera por lo global y por dicha internacionalización de la agenda de género, y si bien los movimientos feministas han establecido una serie de demandas a través de diversas estrategias, el estado, desde una dinámica autoritaria y patriarcal ha procedido a su silenciamiento y a la apropiación de sus discursos. Con esto, el estado saudí ha bloqueado la autonomía de los movimientos feministas y ha continuado con las políticas de segregación de género.

El tercer objetivo específico del artículo ha sido mostrar la rivalidad entre ambos estados como un factor determinante. La rivalidad, basada en la construcción de identidades contrapuestas, tiene un recorrido histórico que se remonta a la década de 1980. La inclusión de Arabia Saudí en un proceso de socialización internacional en el cual las políticas de género han sido la bandera 
del aumento de su actividad diplomática han buscado la legitimación de sus acciones regionales, que tienen como objetivo desbancar a Irán y la presentación de Arabia Saudí ante la comunidad internacional como un estado reformista y comprometido con los derechos de las mujeres.

La inclusión la agenda de género en Arabia Saudí ha formado parte de una política de socialización internacional pero cuyas medidas han respondido más a las presiones globales que a las demandas internas, que han sido silenciadas. Por su parte Irán ha acelerado sus políticas de género en el contexto de un presidente reformista en un proceso de socialización internacional que no responde tanto a la coyuntura política internacional actual como a la trayectoria de las luchas de género en el país.

Las políticas de género son una consecución de múltiples factores. Sin embargo, para comprender estos factores debemos reflexionar dentro de las dimensiones de lo internacional y lo doméstico, teniendo las demandas de los movimientos feministas como factores determinantes y la rivalidad identitaria. Los intereses de legitimación como aliado de occidente de Arabia Saudí frente a Irán pasan por la adquisición de unas medidas de género que, al contrario que en Irán, evitan la internalización de la agenda internacional de género en un proceso que, lejos de reconocer las demandas de los movimientos feministas nacionales, busca su alienación y la apropiación de su discurso.

\section{Bibliografía}

AHMADIAN, Hassan, "How effective is Saudi Araba's 'Counter-Iran Policy'?", AlSharq Forum Analyis, 2017.

AL JAZEERA, "Saudi Arabia 'seeks death penalty' for female activist”, 22 de agosto de 20I8: https://www.aljazeera. com/news/20 I8/08/saudi-arabia-seeks-death-penalty-female-activist- I80822 I I I 33388 I.html [Consultado el 25 de agosto de 2018]

AL JAZEERA, "Saudi king names women to advisory council", 12 de enero de 2018: https://www.aljazeera.com/news/middleeast/20I3/0I/20I3III23462426/97I.html [Consultado el 20 de agosto de 2018]

ALHARETH, Yahya, ALHARETH, Yasra, AL DIGHRIR, Ibtisam, "Review of Women and Society in Saudi Arabia", en American Journal of Educational Research, 2015, pp. I2I-I25.

AL-KHAMRI, Hana, "Why did Saudi Arabia lift the driving ban on women only now?, en Al Jazeera, 24 de junio de 20 18: https://www.aljazeera.com/indepth/opinion/saudi-arabia-lift-driving-ban-women- I 8062 I 203632446. html [Consultado el I9 de agosto de 2018]

ALOUFI, Alanoud, Gender and National Identity in Saudi Arabia, San Francisco State University, San Francisco, 2017.

BARNARD,Anne, ERDBRINK, Thomas, 2018, “Iran and Saudis' Latest Power Struggle: Expanding Rights for Women”, en NYTimes, 29 de diciembre de 2017:

https://www.nytimes.com/20I7//2/29/world/middleeast/iran-saudi-women.html [Consultado el 10 de junio de 2018]

BBC NEWS, “Profile: Shirin Ebadi”, 27 de noviembre de 2009: http://news.bbc.co.uk/2/hi/middle_east/3I8I992.stm [Consultado el 01 de septiembre de 2018]

BBC NEWS, "Archbishop of Canterbury meets Saudi's Crown Prince", 8 de marzo de 2018: http://www.bbc.com/news/ukpolitics43330696 [Consultado el 25 de agosto de 2018]

BESSIS, Sophie, Les árabes, les femmes, la liberté, Alianza Editorial, Madrid, 2008.

BUZAN, Barry, “The 'Standard of Civilisation' as an English School Concept”, en Millennium - Journal of International Studies, Vol. 42, 20I4, pp. 576-594.

DW ENGLISH, “Iranian women look to conquer world of weightlifting”, 24 de abril de 2018. https://www.dw.com/es/actualidad/s-30684 [Consultado el I5 de julio de 20I8]

FADAEE, Farshid, Iran and Saudi Arabia, and the Perfect Storm in the Persian Gulf, Uppsala University, Department of Peace and Conflict Research, 2017.

FARZAMNIA, Nadereh, Irán: De la Revolución Islámica a la Revolución Nuclear, Síntesis, Madrid, 2009.

FINNEMORE, Martha, SIKKINK, Kathryn, “International Norm Dynamics and Political Change”, en International Organization at Fifty: Exploration and Contestation in the Study of World Politics, 1998, pp. 887-9I7.

FREEDOM HOUSE, "Freedom House: Saudi Arabia Profile", 2017: 
https://freedomhouse.org/report/freedom-world/20I7/saudi-arabia [Consultado el I5 de agosto de 20I8]

FRIEDMAN, Thomas L.,"Saudi Arabia's Arab Spring, at Last”, en The New YorkTimes, 23 de Noviembre de 2017: https://www.nytimes.com/20I7/I I/23/opinion/saudi-prince-mbs-arab-spring.html [Consultado el I6 de agosto de 2018]

GAUSE III, F. Gregory, “Fresh Prince:The Schemes and Dreams of Saudi Arabia's Next King”, en Foreign Affairs, Mayo/ Junio de 2018: https://www.foreignaffairs.com/articles/middle-east/2018-03-19/fresh-prince [Consultado el 17 de agosto de 2018]

GOLDBERG, Jeffrey, “Crown Prince: Iran's Supreme Leader 'Makes Hitler Look Good”, en The Atlantic, 2 de abril de 2018: https://www.theatlantic.com/international/archive/2018/04/mohammed-bin-salman-iran-israel/557036 [Consultado el 08 de agosto de 2018].

GRUMET, Tali Rachel, New Middle East Cold War: Saudi Arabia and Iran's Rivalry, University of Denver, Denver, 2017.

HAKAKIAN, Roya, “The Iran-Saudi Arabia Rivalry Has a Silver Lining”, en NYTimes, 27 de diciembre de 20I7: https://www.nytimes.com/2017/I2/27/opinion/iran-saudi-rivalry-women.html [Consultado el 10 de junio de 2018]

HAYKEL, Bernard, “Transformation of Saudi Arabia: Can MBS’s Economic and Religious Reforms Succeed?"” en Princeton University, 19 de julio de 2018: https://www.youtube.com/watch?v=ma IkqF5elb8 [Consultado el 16 de agosto de 2018]

HOBSBAWM, Eric, RANGER, Terence, The invention of tradition, Cambridge University Press, Cambride, 1983.

HOMEWOOD, Brian, “Iran's Rouhani pledges women to get access to stadiums: FIFA chief”, en Reuters, 2 de marzo de 2018: https://www.reuters.com/article/us-soccer-fifa-iran/irans-rouhani-pledges-women-to-get-accessto-stadiums-fifa-chief-idUSKCNIGEIEJ [Consultado el 10 de junio de 2018]

HUMAN RIGHTSWATCH, “Saudi Arabia: End Male Guardianship”. https://www.hrw.org/endmaleguardianship [Consultado el 21 de agosto de 2018].

JAZMATI, Ramsi, “Arabia Saudí: aliado imprescindible para Europa y España”, en Instituto Español de Estudios Estratégicos, 16 de febrero de 2017.

JOHNSON, Boris, "Saudi Reformer Mohammed Bin Salman Deserves Our Support", en The Times, 28 de febrero de 2018: https://www.thetimes.co.uk/article/boris-johnson-saudi-reformer-mohammed-bin-salman-deservesour-support-k5lhkhqlh [Consultado el 05 de Abril de 2018]

LABANI MOTLAGH, Sepideh, Los movimientos de mujeres feministas en Irán: un análisis desde la perspectiva de la teoría feminista, Universidad Autónoma de Madrid, Madrid, 2015.

LA MONCLOA, "El presidente del Gobierno recibe al príncipe heredero de Arabia Saudi”, 12 de abril de 20I8: https://www.lamoncloa.gob.es/presidente/actividades/Paginas/2018/I204/8-visitaarabia.aspx [Consultado el 25 de agosto de 2018]

LE RENARD, Amélie, “Only for Women: The State and Reform in Saudi Arabia”, en The Middle East Journal, Vol. 62, 2017, pp. 610-629.

LE RENARD,Amélie, "Personal Development and the "Rights of Woman”:Women's Appropiation of Religion in Saudi Arabia”, en SciencesPo, pp. I- I8.

MAJIN, Sokrollah Kamari, "Iranian and Saudi Cultural and Religious Identities: Constructivist Perspective”, en Open Journal of Political Science, 7, 217, pp. 65-8I.

MARTíN, Javier, La Casa de Saúd, Catarata, Madrid, 2013.

McCALL, Corey, COLLEGE, Elmira, “Ambivalent Modernities: Foucault's Iranian Writings Reconsidered”, en Foucault Studies, 15, 2013, pp. 22-5I.

MÉNORET, Pascal, Arabia Saudí: El reino de las ficciones. Bellaterra, Barcelona, 2003.

MERINERO MARTÍN, María José, Irán: hacia un desorden prometedor, Los Libros de la Catarata, Madrid, 200 I.

MERINERO MARÍN, María José, Resistencia Creadora en Irán, Biblioteca Nueva; Universidad de Extremadura, Madrid, 2007.

NAYEREH,Tohidi, “Women's rights and feminist movements in Iran” en International Journal of Human Rights, 2016. http://sur.conectas.org/en/womens-rights-feminist-movements-iran/ [Consultado el 26 de agosto de 2018]

OSIEWICZ, Przemysław, “Ideological Determinants of the Current Saudi-Iranian Rivalry in the Middle East”, en Poznan University, Poznan, 2016.

ROY, Josee, “Contemporary Women's Activism”, CRSA Academic Journal of Religion, 20I5, pp. 63-68.

ROY, Josee, “Contemporary Women's Activism and Reform in Saudi Arabia”, CRSA: Concordia Religion Students'Association, Vol. I, 20I5, pp. I-6.

SALEH AL KHAMSI, Sarah,ABUD-ALAZIZAL KHIELFE, Shorook, "Feminist Movement Obstacles in Saudi Arabia”, en Journal of Social Sciences of Princess Nora Bint Abdulrahman University, 20 I6, pp. 95- I0I.

SAPRAC, Saudi American Public Relation Affairs Committee: http://www.saprac.org/ [Consultado el 25 de agosto de 2018]

SHIBABI,Ali, “Ali Shibabi discusses the end of Saudi Arabia's ban on women driving with bloomberg”, en Arabia Foundation, 29 de marzo de 2018:

http://www.arabiafoundation.org/videos/ali-shihabi-discusses-the-end-of-saudi-arabias-ban-on-women-driving-withbloomberg/[Consultado el 20 de agosto de 2018]

SKORNICKI,Arnault, La Gran Sed de Estado: Michel Foucault y las Ciencias Sociales, Dado, Madrid, 2017

THE ECONOMIST, “At last Saudi women will be allowed to take the wheel”, 30 de septiembre de 2017: https:// 
www.economist.com/leaders/2017/09/30/at-last-saudi-women-will-be-allowed-to-take-the-wheel [Consultado el 20 de agosto de 2018]

THE FINANCIAL TIMES, "Saudi Arabia arrests campaigners who challenged women driving ban”, I 8 de mayo de 2018. https://www.ft.com/content/bfcdfffc-5aa7-I le8-bdb7-f6677d2el ce8 [Consultado el 26 de agosto de 2018]

TICKNER, J.Ann, "What Is Your Research Program? Some Feminist Answers to International Methodological Questions" en Interntional Studies Quarterly, Vol. 49, 2005, pp. I-2I.

Vision2030 Official Webpage: http://vision2030.gov.sa/en [Consultado el 20 de agosto de 2018]

WALBY, Sylvia, Theorizing Patriarchy, Basil Blackwell, Oxford, 1990.

WENDT, Alexander, Social Theory of International Relations, Cambridge University Press, Nueva York, 2003

WORLD ECONOMIC FORUM, “Global Gender Gap Report”, 20 16: http://reports.weforum.org/global-gendergap-report-0 |6/economies/?doing_wp_cron=| 5350203 | 5.007503986358642578| 250\#economy=SAU [Consultado el 16 de agosto de 2018]

YOUNGS, Gillian, "Feminist International Relations: a contradiction in terms? Or: why women and gender are essential to understand the world 'we' live in", en International Feminist Journal of Politics / International Affairs, Vol. I, 2004, pp. 75-87.

YUBERO PARRO, Beatriz, "Irán en la era de la Administración Trump” en Documento MARCO; Instituto Español de Estudios Estratégicos, 18 de diciembre de 2017, pp. I-4I. 
Relaciones Internacionales

Número 42 • Octubre 2019 - Enero 2020

Grupo de Estudios de Relaciones Internacionales

Universidad Autónoma de Madrid 


\section{RELACIONES INTERNACIONALES}

Revista académica cuatrimestral de publicación electrónica Grupo de Estudios de Relaciones Internacionales (GERI)

Universidad Autónoma de Madrid, España

https://revistas.uam.es/relacionesinternacionales

ISSN 1699 - 3950

f facebook.com/RelacionesInternacionales

3. twitter.com/RRInternacional

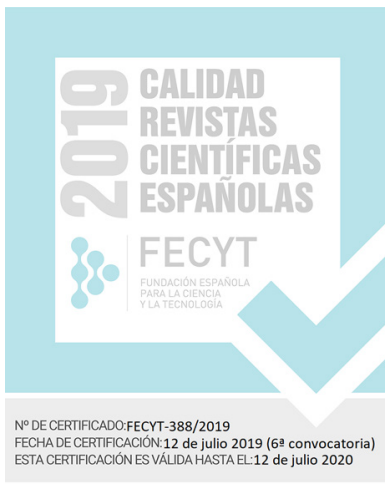

